Laboratorio de Arte, 7-1994 http://dx.doi.org/10.12795/LA.1994.i07.10

\title{
NUEVAS APORTACIONES SOBRE PLATERÍA MEJICANA EN VILLARRASA
}

\author{
por Juan Miguel González Gómez y Manuel Jesús Carrasco Terriza
}

\begin{abstract}
En el presente estudio identificamos las piezas de orfebrería que el indiano Pedro Ximénez Delgado donó en 1675 a la ermita de la Virgen de los Remedios de Villarrasa. En el legado, inédito hasta ahora, se reseña un frontal de plata, un cáliz, una patena, dos vinajeras con salvilla y un par de blandones, todo de plata mejicana. Y, además, catalogamos por primera vez el templete-ostensorio de la parroquial de San Vicente Mártir de Villarrasa como obra de orfebrería mejicana hacia 1675.

Saint Vincent parrish, at Villarrasa (Huelva) has an interesting silver collection, and between its peaces the best may be the altar of Our Lady of "Los Remedios", coming from America at the end of XVIIth century. After our recent investigation, we found some new pieces, also caming from America, during the Spanish rule.
\end{abstract}

La parroquia de San Vicente Mártir de Villarrasa, en la Tierra Llana de Huelva, conserva una interesante colección de orfebrería. Entre sus valiosas piezas, destaca, como se sabe, el frontal de altar de la Virgen de los Remedios, fruto del mecenazgo americano. Sin embargo, otras han permanecido en el anonimato hasta el momento. Tras nuestra reciente investigación, damos a conocer la identificación de algunas obras de platería indiana de la segunda mitad del Seiscientos. De esta forma, contribuimos a esclarecer y aumentar la prestigiosa nómina de la orfebrería hispano-americana en la actual provincia onubense '.

1. HEREDIA MORENO, María del Carmen, La orfebrería en la provincia de Huelva, Excma. Diputación Provincial de Huelva, Instituto de Estudios Onubenses «Padre Marchena», Huelva, 1980. T. II,. GONZÁLEZ GÓMEZ, Juan Miguel, El mecenazgo americano en las iglesias de Cumbres Mayores, en Actas de las Primeras Jomadas de Andalucía y América, Sevilla, 1980, págs. 294-301. HEREDIA MORENO, María del Carmen, Valoración de la platería hispanoamericana de época colonial en la provincia de Huelva, en Huelva y América, t.II, págs. 287-309, Diputación Provincial, Huelva, 1993. 


\section{EL LEGADO DE PEDRO XIMÉNEZ DELGADO.}

Movido por sus inquietudes históricas, el entonces seminarista, y luego sacerdote, don Francisco Infantes de Cos, copió el 23 de agosto de 1935, un interesantísimo documento de legado de plata indiana ${ }^{2}$. Por él sabemos que Pedro Ximénez Delgado, vecino de Villarrasa, gran devoto de la Virgen de los Remedios, donó el 14 de febrero de 1675 un frontal de plata, un cáliz con su patena, dos vinajeras con su salvilla, y un par de blandones, para el culto de la ermita de la Misericordia. Dice así el documento:

«Ante Jerónimo Herrera, Secretario, en 14 de febrero de 1675. Pedro Ximénez Delgado, vecino de esta villa de Villarrasa digo que por cuanto yo tengo mucha devoción a la Virgen Santísima de los Remedios, sita en esta dicha villa, y habiendo ido a las Indias y vivido en la ciudad de México, su Divina Majestad fue servido de traerme con prosperidad a esta villa, y en lo cual y en aumento de gracias, otorgo y conozco por la presente carta que hago grazia y donazión buena, pura, perfecta, yrrevocable, a la dicha Virgen de los Remedios, para maior aumento y selebrazión del culto divino en su altar, de un FRONTAL DE PLATA labrado a martillo con extremos sobredorados = UNA CALIS, PATTENA, DOS VINAJERAS Y UNA SALVILLA DE PLATA SOBREDORADA, Y DOS BLANDONES DE PLATA BLANCA, y desde luego todo lo cedo, renuncio y traspaso en la Hermandad de la Cofradía de la Santa Misericordia, sita en esta villa, donde está colocada la dicha imagen, a quien nombro por administradora y tenedora de las dichas piezas [...]».

El generoso donante estableció, líneas más abajo, las condiciones siguientes:

«1. Que el Hermano Mayor de dicha Cofradía de la Santa Misericordia, por sí y en nombre de los hermanos de ella, ha de aceptar esta escritura, y obligarse a la seguridad y estabilidad de las dichas piezas de plata.

2. Que la Cofradía ha de tener y tenga en sí la dicha plata para el servicio del altar de Nuestra Señora de los Remedios, y no las ha de poder, ni parte de ellas, empeñar, ni vender, ni prestar fuera de esta villa, más que tan solamente a la Iglesia Parroquial de ella, para las fiestas que hubiere menester las dichas prendas o algunas de ellas [...].

3. Que cuando la dicha Cofradía nombrare Hermano Mayor en ella, tenga obligación de entregarle las dichas piezas de plata y en inventario, sin que en esto haya omisión alguna, porque de haberla, con el transcurso del tiempo se pueden enajenar.

2. (A)rchivo (P)articular de (A)ntonio (R)íos (R)amos. Villarrasa. "Donación del frontal de plata a la Virgen de los Remedios. Año 1675". 
4. Que si la dicha Hermandad prestare por sí o su Hermano Mayor, o por mandato de cualquier juez o prelado eclesiástico o secular, las dichas piezas o algunas de ellas para fuera de esta villa, pueda entrar en las dichas prendas el mayordomo de fábrica de la Iglesia Parroquial de San Vicente Mártir, de esta villa, y tenerlas en la dicha fábrica con las mismas calidades y condiciones que queda referido, porque desde luego para entonces que llegue el caso de prestarla dicha Cofradia las dichas prendas para fuera de esta villa, nombro por administradora y tenedora de ella a la dicha fábrica».

Tras las cláusulas de revocación, sigue la aceptación por parte del Hermano Mayor, que lo era entonces Martín Hidalgo, y concluye con la datación:

"En Villarrasa, a catorce días del mes de febrero de mil seiscientos y setenta y cinco, y los otorgantes a quien yo leí en público dan fe y conozco, lo firmaron, siendo testigos Gabriel Domínguez, Juan Ramos, presbíteros, y Alonso de Rivera, Alcalde ordinario, y vecinos de esta dicha villa.- Pedro Ximénez Delgado.- Martín Hidalgo Cortesano.- Ante mí, Jerónimo de Herrera».

Antonio Ríos Ramos dio a conocer, en 1989 , la noticia relativa al frontal de plata que luce en el altar de la ermita villarrasera ${ }^{3}$, gracias a lo cual figuró como pieza príncipe en la Exposición Plata labrada de Indias. Los legados americanos a las iglesias de Huelva, celebrada en el Monasterio de Santa Clara de Moguer en septiembre-octubre de $1992^{4}$. Ahora, afortunadamente, podemos identificar el resto de las piezas que figuran en el legado.

\section{FRONTAL DE ALTAR}

Materiales: Plata en su color y sobredorada.

Técnica: Repujada y cincelada.

Medidas: 103,5 x 302 cms.

Cronologia: hacia 1675. Fig. 1.

Esta obra de orfebrería barroca mejicana reproduce en plata el modelo de las ricas frontaleras que exomaban los altares, de diversos tejidos, colores y labores, bordados o pintados, a tenor de los tiempos litúrgicos y de la categoría de las fiestas. Solía componerse de un faldón o cuerpo principal, que cubría todo el

3. RÍOS RAMOS, Antonio, Religiosidad popular en Villarrasa, en El Cofrade $\mathrm{n}^{\circ} 4$ (17-XI-1989), págs. 39-43.

4. PALOMERO PÁRAMO, Jesús Miguel, Plata labrada de Indias. Los legados americanos a las iglesias de Huelva. Monasterio de Santa Clara de Moguer. Septiembre-Octubre, 1992, págs. 104-105. 
frente, sobre el que caía horizontalmente una banda, rematada con flecadura de pasamanería, y quedaba flanqueado por dos caídas o cenefas verticales, rematadas con galón. Al centro solía llevar el símbolo iconográfico del titular del templo, o el de la fiesta litúrgica que se celebrara. Por la proximidad con el frontal de Villarrasa, en el tiempo de su composición, y en cuanto a su lugar de origen, es interesante tener presente el lienzo mexicano de la iglesia de San Pedro de la Rúa, de Estella, que reproduce el altar de la Virgen de los Remedios, devoción mexicana, en el que figura un frontal de altar, de polícromos brocados, cuyos roleos vegetales enmarcan un jarrón de azucenas ${ }^{5}$.

El frontal de altar de Villarrasa se compone, pues, de un cuerpo principal, de impecable factura, enmarcado por una banda superior horizontal y dos caídas verticales en sus extremos, de ejecución algo más tosca.

El cuerpo principal queda centrado por una placa, exquisitamente labrada, que reproduce un jarrón de azucenas, símbolo de la pureza virginal de María, rodeado de ces y cartelas doradas, con diseños curvilíneos planos, sobre fondo mate cincelado; quedando todo enmarcado por una guirnalda de laurel. A ambos lados, se desarrollan sendas placas de roleos vegetales simétricos, que parten de unas páteras o platos lisos, circulares, dorados, con una flor abierta de ocho pétalos.

La caída superior, más estrecha, consiste en una franja horizontal, compuesta de una pieza central, con óvalo dorado, en el que figura el trigrama de Jesús -IHS - coronado por la cruz, enmarcado por una tarja en blanco. Cinco placas rectangulares a cada lado se ornamentan con una corola central dorada, de cuatro pétalos, envuelta por dos grandes hojas de acanto en blanco, con el peciolo dorado. Por debajo discurre seguido un galón de roleos vegetales. A modo de flecos, se dispone una secuencia de hojas estilizadas, en cuyo diseño se unen una cartela plana, en blanco, y una hoja dorada, con tallo y nervios labrados.

Las cenefas laterales constan de un óvalo central dorado, enmarcado por cartela en blanco, de la que parten, tanto por arriba como por abajo sendas hojas de acanto, con tallos curvos dorados. En el óvalo de la derecha del altar figura el emblema coronado de la Virgen -MARÍA-, y en el de la izquierda el de su esposo San José -IOSEPH-. Quedan separados del cuerpo principal por una flecadura de hojas más pequeñas y un galón en forma de guirnalda de laurel, el mismo galón que enmarca todo el conjunto de la frontalera.

Notemos que el repertorio iconográfico, plasmado en esta frontalera mejicana, alude de un modo directo a la Sagrada Familia: Jesús, María y José.

5. HEREDIA MORENO, María del Carmen, Mercedes DE ORBE SIVATTE, Asunción DE ORBE SIVATTE, Arte hispanoamericano en Navarra. Plata, pintura y escultura. Gobierno de Navarra, Pamplona, 1992, págs. 214-215. 


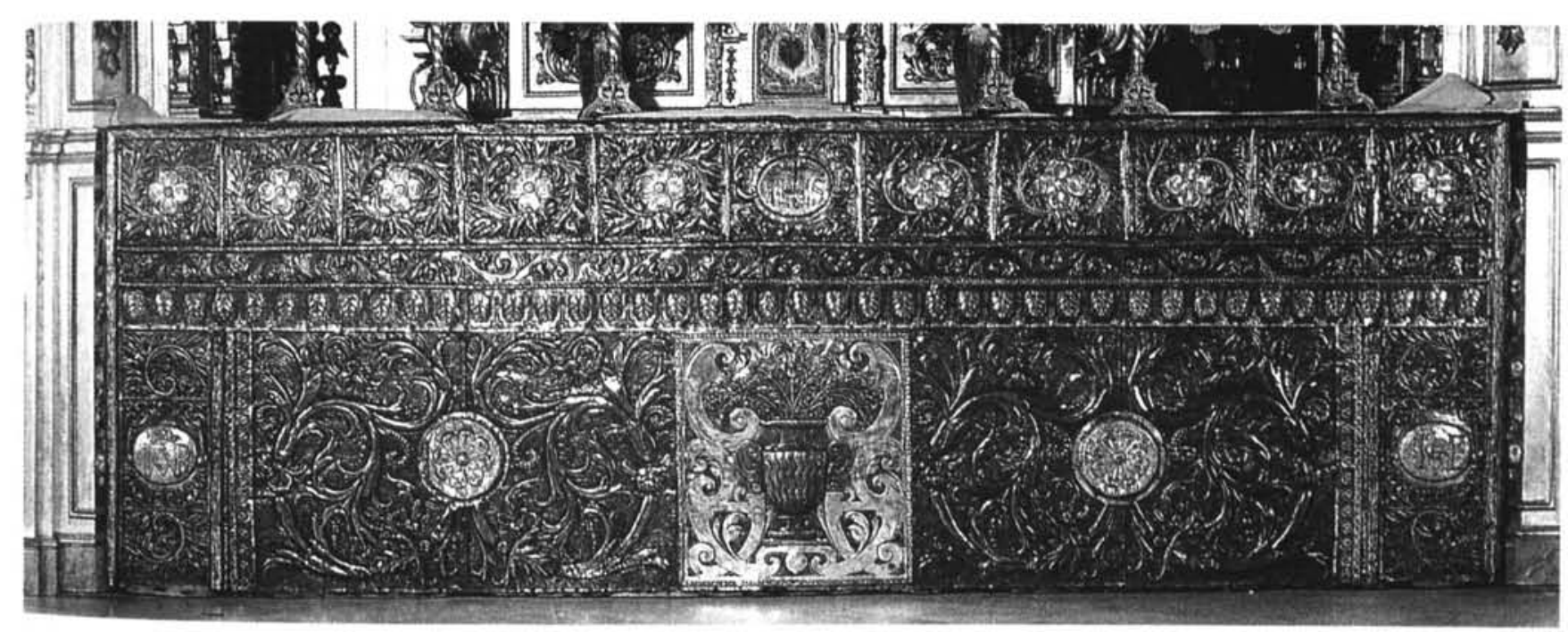

Fig. 1. Frontal del Altar. 
Su estrecha similitud estilística al altar del Stmo. Sacramento de la Iglesia Prioral del Puerto de Santa María, obra de José de Medina, fechada en $1687^{6}$, nos permite relacionar el frontal de Villarrasa con dicho autor o taller mexicano.

El frontal, publicado por Heredia ${ }^{7}$, Ríos $\operatorname{Ramos}^{8}$, y Sanz-Mejías ${ }^{9}$, figuró, como hemos dicho, en la exposición Plata labrada de Indias, que tuvo lugar en septiembre y octubre de 1992, en el Monasterio de Santa Clara de Moguer ${ }^{10}$. El 14 de junio de 1993 sirvió al altar en el que ofició la eucaristía S.S. el Papa Juan Pablo II, en su visita apostólica a Huelva ${ }^{11}$.

\section{CÁLIZ}

Materiales: plata sobredorada.

Técnica: fundido, repujado y cincelado.

Medidas: $25 \mathrm{cms}$. de altura; $14,5 \mathrm{cms}$. de base; $8,5 \mathrm{cms}$. de copa.

Cronología: hacia 1675. Fig. 2.

En la donación de Pedro Ximénez Delgado figura, como hemos visto, un cáliz, con su patena, que identificamos con la pieza que describimos a continuación.

La estructura del cáliz sigue los modelos puristas de la Península de la primera mitad del siglo XVII, que en México se prolongan hasta entrado el Setecientos.

El amplio pie circular se compone de tres cuerpos escalonados decrecientes: un plinto de perfil recto, un cuerpo intermedio convexo y un anillo cilíndrico en resalte, con círculo interior cóncavo. El cuerpo central de la base se decora con cuatro artesones. Entre ellos se aplican en relieve otros tantos querubines, fundidos, con alas desplegadas, y cabecitas con abultados bucles a modo de penachos. Completa la ornamentación un fondo punteado de picado de lustre a buril, con motivos simétricos de ces, roleos y zarcillos, que flanquean a los querubines.

6. SANZ, María Jesús, y María Jesús MEJíAS, Platería mexicana en Andalucía Occidental, en Buenavista de Indias, I, 5 (1992), págs. 36-53, láms. en págs. 36, 42-43.

7. HEREDIA MORENO, María del Carmen, La orfebreria en la provincia de Huelva, Huelva, 1980, t. I. pág. 299, láms. 339-340.

8. RíOS RAMOS, Antonio, Religiosidad popular en Villarrasa. Op. cit., págs. 37-43.

9. SANZ, María Jesús, y María Jesús MEJíAS, Platería mexicana en Andalucia Occidental. Op. cit., págs. 36-53, láms. en págs. 50-51.

10. PALOMERO PÁRAMO, Jesús Miguel, Plata labrada de Indias. Los legados americanos a las iglesias de Huelva. Op. cit. En la portada del Catálogo figura el jarrón de azucenas, motivo central de la frontalera.

11. CARRASCO TERRIZA, Manuel Jesús, Huelva presente en los enseres litúrgicos de la Misa del Papa, en Boletín Oficial del Obispado de Huelva, $\mathrm{n}^{\circ} 303$, Número extraordinario conmemorativo de la Visita de S.S. el Papa, 14 junio 1993, págs. 385-386. 


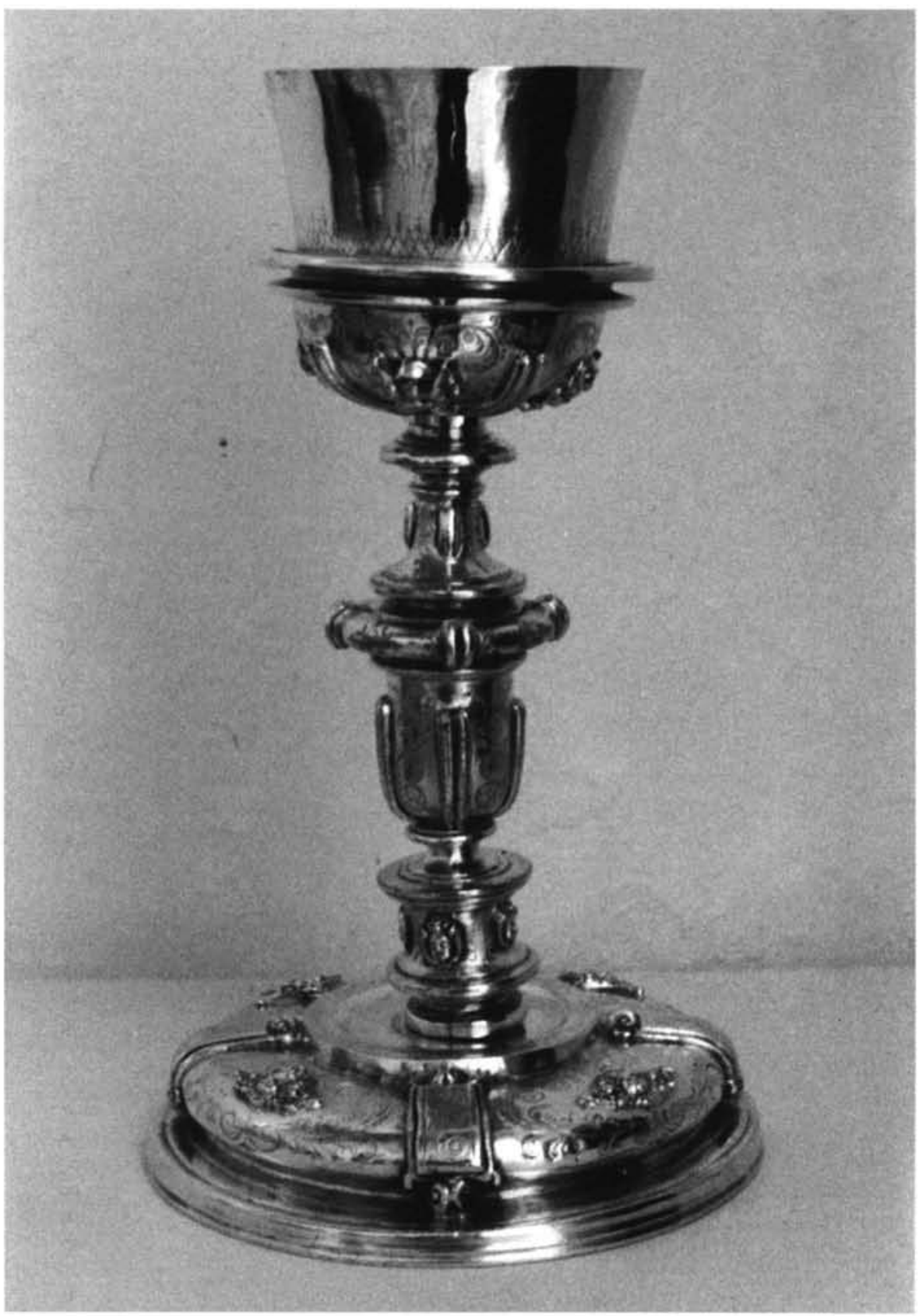

Fig. 2. Cáliz 
En el astil se superponen un tambor o gollete cilíndrico, entre molduras salientes, que ostenta otros cuatro querubes con alas recogidas. El nudo de jarrón semiovoide presenta cuatro pares de gallones y fondos burilados de temática semejante. El toro de coronamiento, muy pronunciado, ofrece idéntica ornamentación. Por último, un cuello troncocónico, enriquecido con cuatro espejos, enlaza con la copa.

La copa acampanada, de perfil ligeramente abierto, queda separada de la subcopa por doble platillo horizontal muy volado. Se ornamenta ésta, a juego con lo precedente, con cuatro gallones pareados y cuatro querubines sobre fondos a buril de ces vegetalizadas y formas foliáceas naturalistas. Sobre el platillo superior se desarrolla una crestería cincelada, de dientes de sierra entrelazados.

Estrecha vinculación estilística presenta esta pieza de orfebrería mexicana con el copón de la iglesia parroquial de Villarrasa ${ }^{12}$, y con los cálices de la parroquial de Villalba del Alcor ${ }^{13}$ y de Paterna del Campd ${ }^{4}$, desaparecido en 1936. Este último podría identificarse con el que formó parte del legado de Francisco de Herrera, según consta en su testamento otorgado en Querétaro en $1654{ }^{15}$. Asimismo podemos relacionarlo con otros ejemplares de origen mexicano, como el de la Parroquia de San Cernín de Pamplona, y otros similares en iglesias navarras ${ }^{16}$.

\section{SALVILLA}

Materiales: Plata dorada.

Técnica: cincelada, repujada y fundida.

Medidas: $25 \mathrm{cms}$. de largo y $19 \mathrm{cms}$. de ancho.

Cronología: hacia 1675. Fig. 3.

Pedro Ximénez Delgado regaló, junto con el frontal y los blandones, un cáliz con su patena, y unas vinajeras con su salvilla, a juego, para el servicio del altar. Desgraciadamente desaparecieron las vinajeras, y sólo resta la salvilla, que damos a conocer como pieza inédita.

La bandeja, a juego con el cáliz, se encuentra asimismo trabajada en plata dorada, de ondulado y recortado perfil, con grueso reborde, de sección curva, y fondo ovalado rehundido. Descansa sobre un pie de forma ovalada. La ornamentación se realiza, como en el cáliz, por medio de ocho querubines de fundición,

12. HEREDIA MORENO, María del Carmen, La orfebrería en la provincia de Huelva. Op. cit., T. II, pág. 206; t. I, fig. 97, pág. 357.

13. Ibídem, T. II, pág. 197; t. I, pág. 351, figs. 86-87.

14. Ibid. T. I, fig. 88 , pág. 352 .

15. Ibid. T. II, págs. $246-248$.

16. HEREDIA MORENO, María del Carmen, Mercedes DE ORBE SIVATTE, Asunción DE ORBE SIVATTE, Arte hispanoamericano en Navarra. Plata, pintura y escultura. Op. cit., págs. 43-66, Cfr. en especial los núms. 2, 3, 4, 8, 9, 10,11, 12, 13, y 19. 


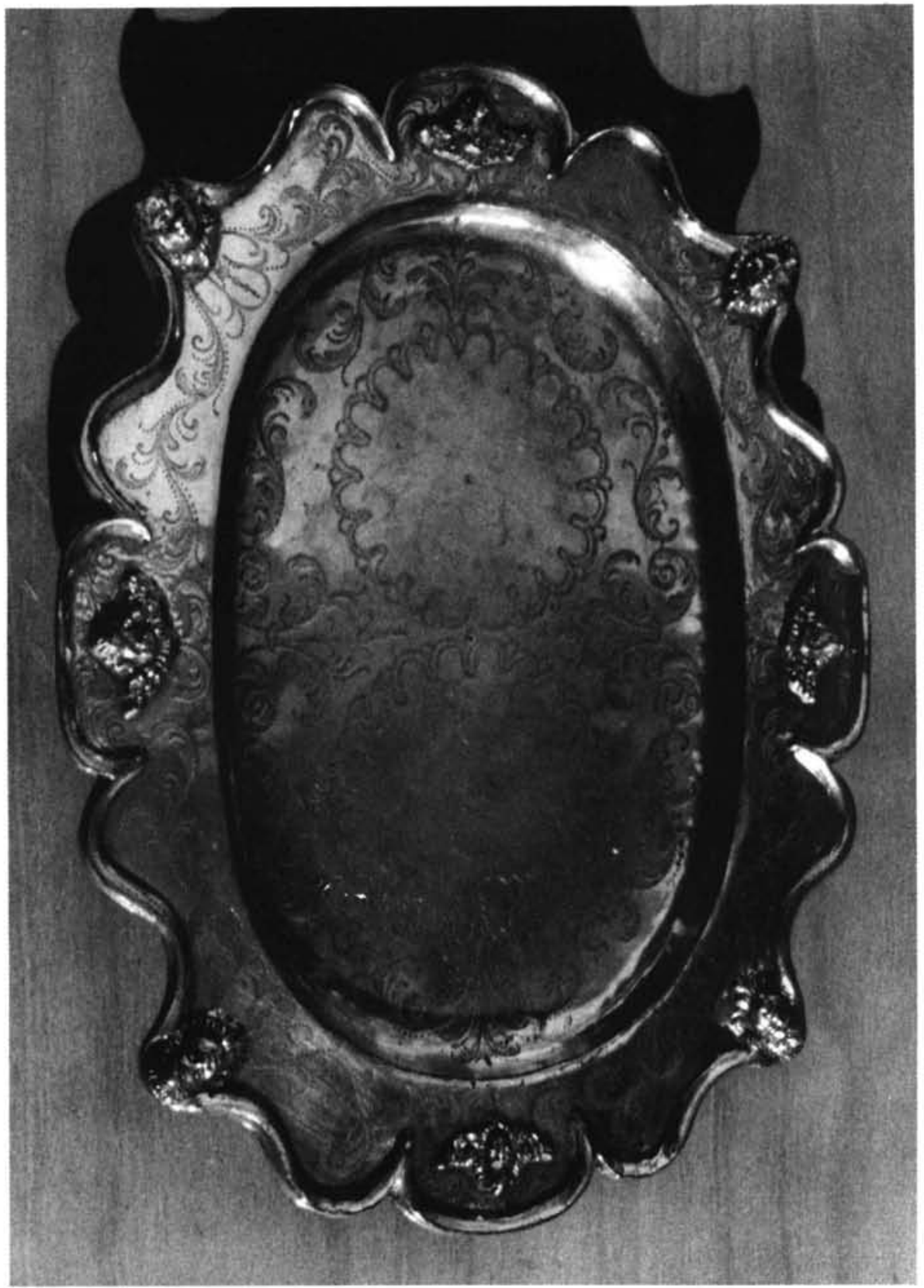

Fig. 3. Salvilla 
aplicados en resalto, y labor de buril. Las cabecitas angélicas se disponen de la siguiente forma: cuatro, con las alas extendidas, se ordenan en cruz; y las cuatro restantes, con las alas recogidas, en aspa. De esta forma se rompe la monotonía del diseño, y se insiste en el dinámico perfil de la pieza. El fondo de la salvilla, donde se puntualiza el lugar que debían ocupar las vinajeras, y el borde superior se decoran con motivos geométricos y con temas vegetales de tallos, roleos y zarcillos, en perfecta simetría, de picado de lustre, hechos a buril.

\section{BLANDONES (DOS)}

Materiales: plata en su color.

Técnica: repujada y cincelada.

Medidas: $43 \mathrm{cms}$. de altura; $20 \mathrm{cms}$. de base; $16 \mathrm{cms}$. de arandela superior. Cronología: hacia 1675. Fig. 4.

Publicado por Heredia en $1980^{17}$, identificamos el par de piezas como parte del legado de Pedro Ximénez Delgado.

Su estructura purista, de rotundas formas globulares, se asemeja a la del cáliz que hemos comentado. Se compone de una base circular, formada por tres cuerpos decrecientes: el primero, plano, de perfil recto; el cuerpo intermedio convexo, que recibe en su superficie los motivos decorativos de cartelas planas y hojas; y un anillo plano de perfil recto, con la parte interior cóncava. El ástil consta de un gollete cilíndrico, ornamentado con hojas planas, y un anillo muy resaltado. Un gran nudo ovoide, con listel que lo fragmenta en dos, recibe asimismo la decoración de hojas planas, que se mezclan con otras más naturalistas, con peciolos y nerviaciones muy marcados. Un esbelto cuello troncocónico enlaza con el cuerpo superior. El coronamiento está formado por una especie de crátera o cáliz, cubierto por un ancho platillo, sobre el que se eleva el cilindro hueco que ha de recibir el cirio; su ornamentación, algo más tosca, está realizada a base de hojas de marcados nervios, dispuestas geométricamente en semicírculos seguidos. Destaquemos la similitud de criterio de ornamentación floral existente entre estas piezas y el frontal de la ermita de Ntra. Sra. de los Remedios. .

Este par de blandones, por expreso deseo del donante, sirvió habitualmente para el culto del altar de la Virgen de los Remedios. Razón por la que el clero de Villarrasa solicitó el 19 de agosto de 1715 la hechura de seis blandones y otras piezas de orfebrería para la iglesia parroquial, «pues los candeleros que sirben en el altar mayor son de asófar y muy ýmfimos» ${ }^{18}$.

17. HEREDIA MORENO, María del Carmen, La orfebrería en la provincia de Huelva, Op. cit., T. II, págs. 204-205; T. I, fíg. 179.

18. (A)rchivo (D)iocesano (H)uelva, Sec. Justicia, Villarrasa, caja 559, Año 1715, «Sobre haser 6 blandones de plata y unos siriales de lo mesmo". 


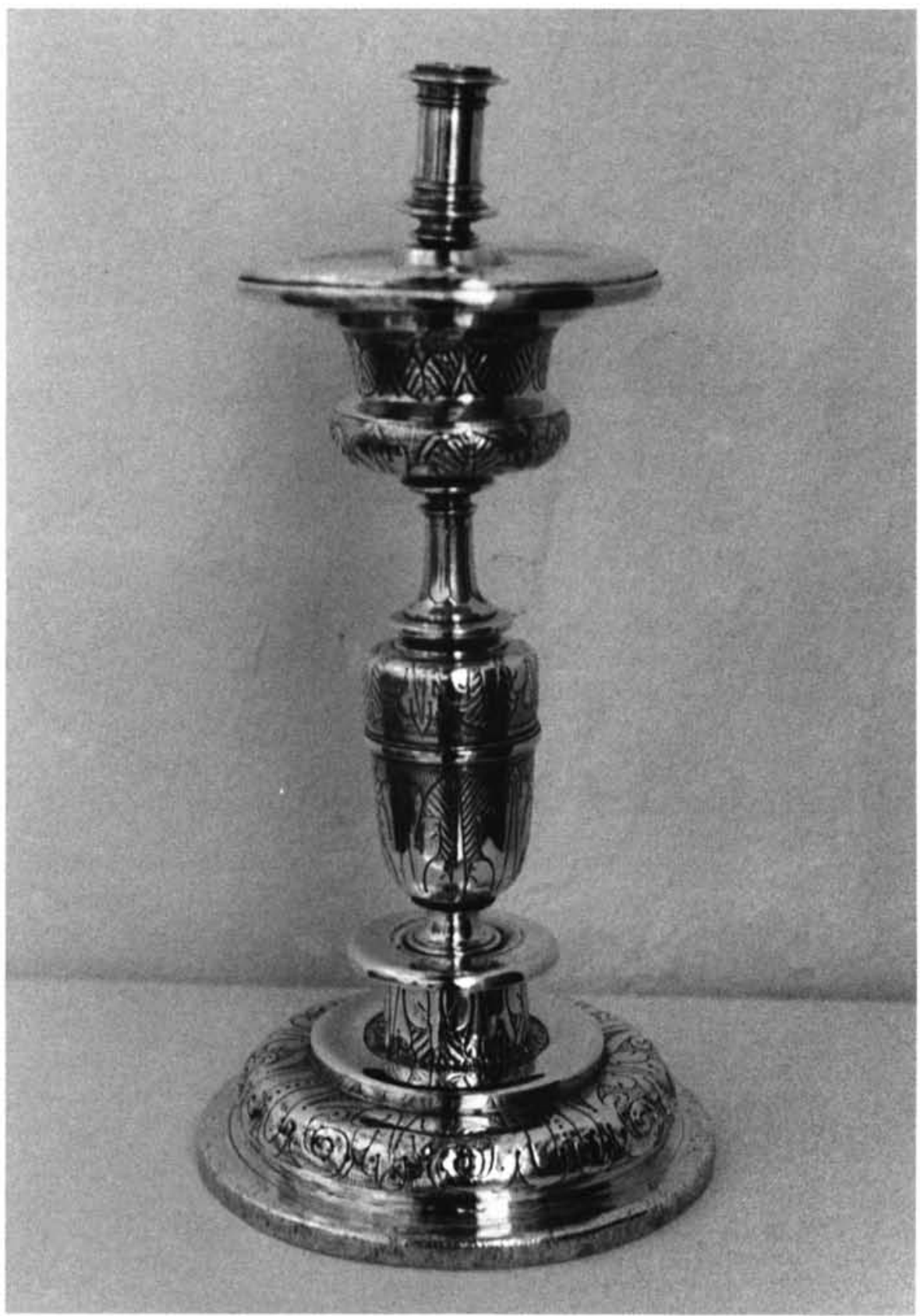

Fig. 4. Blandones. 


\section{TEMPLETE-OSTENSORIO.}

Materiales: Plata dorada.

Técnica: fundida, cincelada y repujada.

Medidàs: $78 \mathrm{cms}$. de altura; plinto de madera $7 \mathrm{cms}$. Total, $85 \mathrm{cms}$. de altura y 34 cms. de base.

Marcas: Punzón de la ciudad de Méjico, reproducido tres veces en los distintos cuerpos del templete.

Cronología: hacia 1675. Fig. 5.

Aunque no figura textualmente en la donación de Pedro Ximénez Delgado, realizada en 1675 , podemos garantizar su procedencia mexicana, gracias a la marca de la ciudad, por tres veces repetida. Podría deberse a otra donación del mismo Ximénez a la Hermandad Sacramental o a la Parroquia, o bien a un legado de otra persona distinta, aunque próxima en su datación.

La pieza que nos ocupa es un ostensorio eucarístico procesional, como evidencian su altura y su peso. Su finalidad era la adoración a la Sagrada Eucaristía en procesión teofórica en el día del Corpus Christi, fiesta, como es sabido, instituida por el Papa Urbano IV el 11 de agosto de 1264, y confirmada por Clemente V en 1312. Aunque la Bula de Urbano IV no alude expresamente a la procesión, parece casi presuponerla o inspirarla. Y de hecho así sucedió en toda la cristiandad. Como afirma Righetti, «todo lo que el celo del clero y la fe ardiente del pueblo, secundado por sus gobernantes, pudo encontrar de pomposo, de rico, de sumamente decorativo, todo fue admitido al servicio del Rey de la gloria, para hacer más triunfal su paso por las calles de los barrios y de las ciudades" ${ }^{19}$.

Una de las formas más comunes de exponer el Santísimo Sacramento en procesión fue el del tabernáculo o templete. Estas piezas a veces alcanzan alturas monumentales, y son situados en carrozas o pasos, portados por sacerdotes. La forma de templete o tabernáculo. rodeado de honor y triunfo, hace simbólica alusión al Prólogo de San Juan: «El Verbo se hizo carne y habitó entre nosotros, y hemos visto su gloria, gloria como de Unigénito del Padre, lleno de gracia y de verdad" ${ }^{20}$. Idea que amplifica en el libro del Apocalipsis: "He aqui la morada de Dios con los hombres: Habitará con ellos y ellos serán su pueblo, y Dios, habitando realmente en medio de ellos, será su Dios» ${ }^{21}$. Toda la tradición veterotestamentaria sobre el templo de Dios, el Sancta Sanctorum, como lugar de la presencia de Dios, encuentra cumplimiento en esta tipología de ostensorio eucarístico.

19. RIGHETTI, Mario, Historia de la Liturgia, t. I, BAC 132, Madrid, 1955 págs. 872-873.

20. Jn. $1,14$.

21. Ap. $21,3$. 


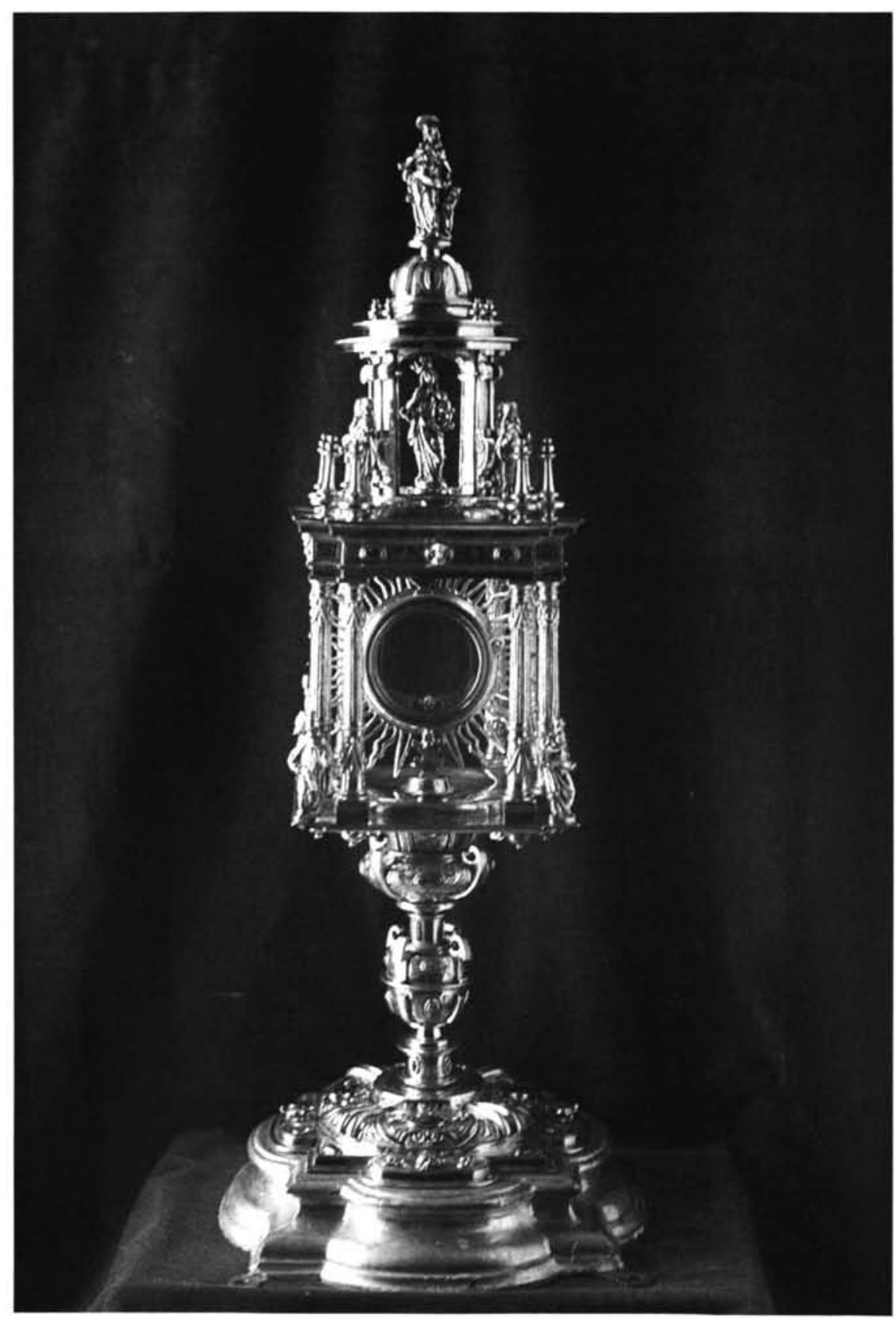

Fig. 5. Templete-Ostensorio. 
Como iconografía complementaria, el templete de Villarrasa relaciona a Jesucristo eucaristizado con María y con José, como el frontal de la Virgen de los Remedios. La presencia de los cuatro Doctores y Padres de la Iglesia Latina, junto con cuatro santos, Doctores y Doctoras, confirma la doctrina católica.

Hagamos notar la relación del repertorio iconográfico con la Orden carmelita descalza, por la temática mariana y josefina, y por la presencia de los santos de la Orden, Santa Teresa y San Juan de la Cruz. En Hispanoamerica, los carmelitas reformados centraron su actividad exclusivamente en el virreinato mexicano ${ }^{22}$.

El templete de plata dorada de la parroquial de Villarrasa se alza sobre una plataforma de madera dorada mixtilínea, cuadrilobular, con cuatro arandelas en los vértices para su fijación en custodia procesional. Documentalmente aportamos que en 1661 el Visitador General del Arzobispado de Sevilla, don Pedro de Miranda y Santillán, mandó, entre otras cosas, que se hiciera «una custodia de madera dorada con sus bidrieras para el día del Corpus Christi en que baia su Divina Magestad» ${ }^{23}$.

En su interior se debía instalar, por consiguiente, el templete-ostensorio que nos ocupa. Su basamento mixtilíneo, cuadrilobular, de perfil recto, se fija al soporte lígneo con cuatro tornillos, cuyas cabezas adoptan formas de hojas carnosas. En los ángulos hay sendos triángulos con botones de esmalte nielado, en tonos azules y verdes, rodeados de labor de buril, de picado de lustre. Los lóbulos presentan decoración de cartelas con hojarascas y fondos matizados y rayados. El segundo cuerpo de la base es circular, con perfil redondeado. La estructura ornamental queda configurada, a partir de este momento, con la disposición de los distintos elementos formando ejes en aspa con los ángulos de la base, y en cruz con los lóbulos. Cuatro pares de gallones compartimentan el círculo. Y cada sector deja ver una cartela con su correspondiente cabujón central, de esmalte champlevé, los mayores de todo el conjunto, entonados a base de azules, verdes y ámbar. Remata el basamento un cilindro de perfil plano y fondo cóncavo, con decoración esgrafiada de ces contrapuestas y gallones.

El astil balaustral se compone de tres elementos. El inferior es un tambor cilíndrico, delimitado por salientes platillos, que se enriquece con pequeños cabujones de esmalte, a juego con los anteriores, situados en línea con los ángulos interiores, Entre ellos hay ces contrapuestas punteadas. A continuación, el nudo ovoide achatado, dividido en dos partes por otro platillo, presenta en la zona inferior cuatro gallones, con cartelas y botones de esmalte entre ellos. En la zona superior se distribuyen cuatro asas, con sus correspondientes cartelas y cabujones

22. BORGES, Pedro, Las Ordenes religiosas, cap. 12. de Historia de la Iglesia en Hispanoamérica y Filipinas, t. I, BAC, Madrid, 1992, págs. 226-227. LOPETEGUI, León, y Félix ZUBILLAGA, Historia de la Iglesia en la América española, t. I, BAC, Madrid, 1965, págs. 732-734.

23. A.D.H., Sec. Justicia, Villarrasa, caja 557. Solicitud de Juan Ramírez, mayordomo de fábrica, para la ejecución de una cruz de plata y una custodia de madera. Sevilla, 1661, noviembre, 16. 


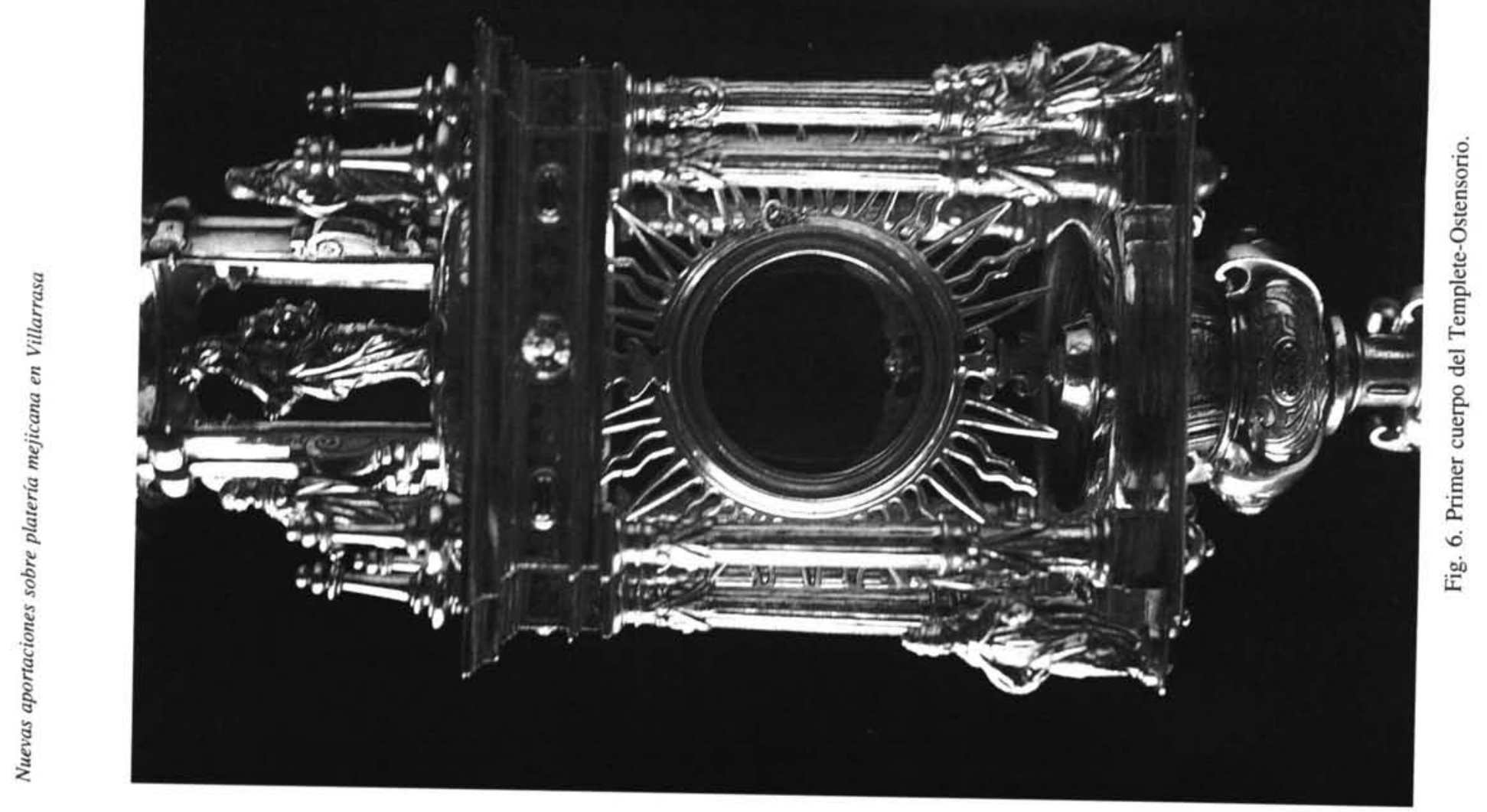


de esmalte nielado, en marcada responsión con lo anterior. Un cilindro con resaltos en línea con las precedentes asas, enlaza con la copa. Un tercer elemento es la taza superior, que sirve de soporte al templete. El sector inferior, panzudo, se decora con cuatro asas y otras tantas cartelas y botones de esmalte nielado, con fondos rayados. $\mathrm{Y}$ el superior presenta cuatro pares de lesenas con sus correspondientes cartelas y cabujones de esmalte entre ellas.

El templete, propiamente dicho, (fig. 6) se compone de dos cuerpos superpuestos y decrecientes. El bajo, de planta cruciforme, en origen, se completó en los ángulos, añadiéndole sendas chapas cuadradas para soportar las figuras que exornan los extremos del mismo. Cada flanco exhibe dos columnas toscanas, sobre plintos, con el tercio inferior decorado con paños colgados y frutas. El resto del fuste, acanalado, luce nuevamente en lo más alto paños y pomas colgadas. Ambas columnas reciben un entablamento rectilíneo, cuyo friso ostenta un querubín flanqueado por botones de esmalte nielado y ces contrapuestas, realizadas a buril. El espacio interior se cierra con un casquete esférico decorado con gallones pareados y cartelas lisas, que brillan sobre un fondo mate y rayado.

En el centro, por fin, se sitúa el gran sol o viril de rayos agudos y flameantes calados, que ha de recibir la Sagrada Forma. La adopción del formato solar para adorar la presencia real de Jesucristo en la Eucaristía enlaza con la tradición bíblica, que califica a Jesús como «sol que nace de lo alto, para iluminar a los que viven en tinieblas y sombras de muerte, para guiar nuestros pasos por el camino de la paz» ${ }^{24}$. Cristo lo ratifica con sus palabras: «Yo soy la luz del mundo; el que me sigue no anda en tinieblas» ${ }^{25}$.

Por último, entre las columnas de los ángulos se añaden los cuatro Padres y Doctores de la Iglesia Latina: San Gregorio Magno, con tiara, capa pluvial, báculo (perdido) en la mano izquierda; San Jerónimo, con el capelo cardenalicio sobre la espalda, libro en la mano derecha y báculo (extraviado) en la otra; San Ambrosio, revestido de pontifical, con mitra, libro en la diestra y báculo (desaparecido) en la siniestra; y San Agustín, también de pontifical, con libro y casa -símbolo de la Ciudad de Dios- en la izquierda y fragmento del báculo en la derecha.

Los cuatro Padres de la Iglesia de Occidente, como Obispos y sucesores de los Apóstoles, representan la Tradición; o sea, la transmisión viva y completa del Evangelio: «Esta Tradición, con la Escritura de ambos Testamentos, son el espejo en que la Iglesia peregrina contempla a Dios, de quien todo lo recibe, hasta el día en que llegue a verlo cara a cara, como Él es (cfr. I Jn. 3,2)» ${ }^{26}$. Fueron declarados Doctores de la Iglesia por Bonifacio VIII, el 20 de septiembre de 1295.

24. L.. 1, 78-79.

25. Jn. 8, 12.

26. CONCILIO VATICANO II. Const. Dei Verbum, 7. 


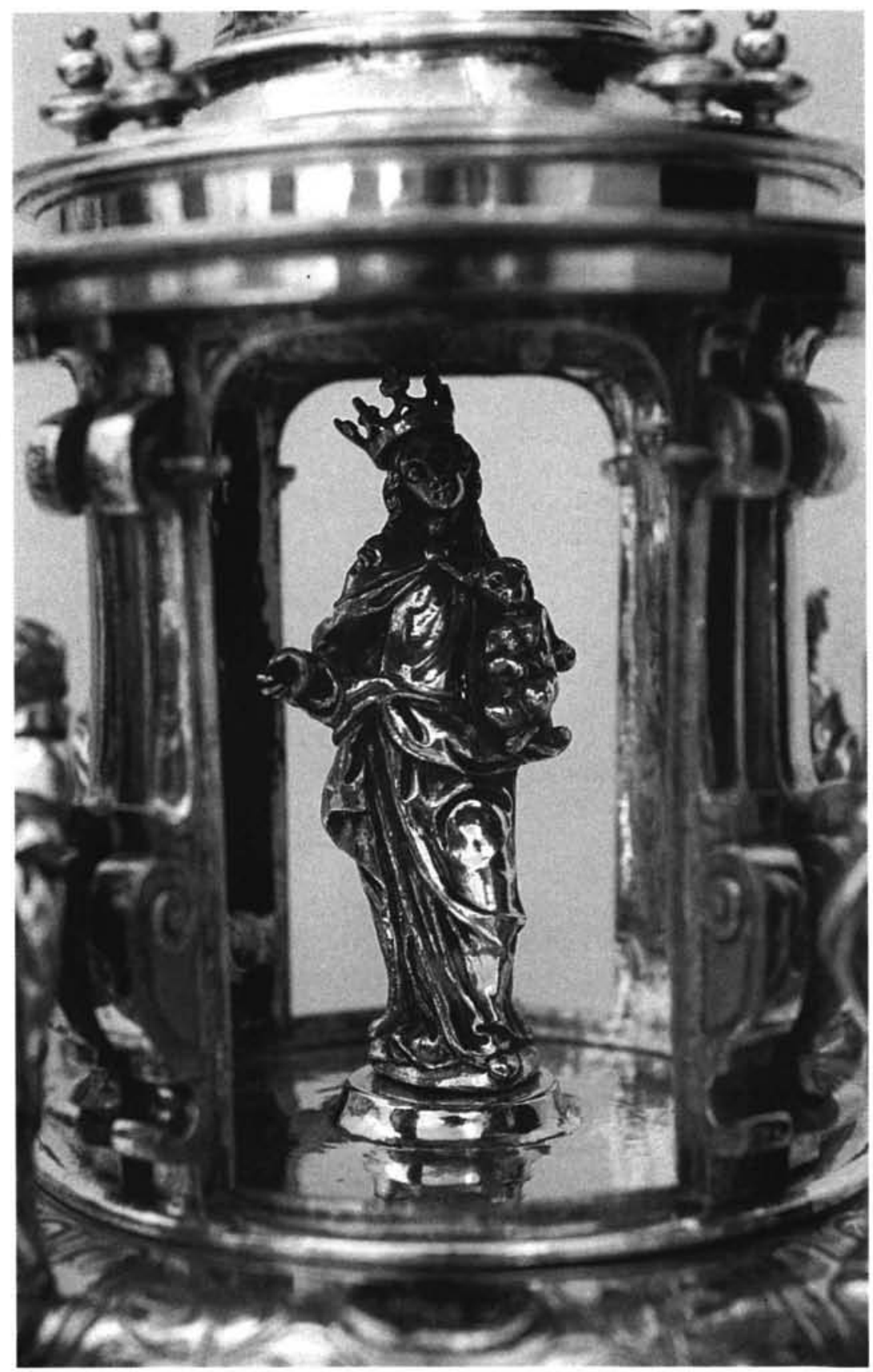

Fig. 7. Segundo cuerpo del Templete-Ostensorio. 
La plataforma superior, cruciforme, se fija a las columnas inferiores por medio de sendas perinolas, de esbelto y airoso formato. Sobre ella asienta el basamento circular del segundo cuerpo, con cuatro esmaltes semejantes a los anteriores y decoración esgrafiada de ces. Entre las referidas perinolas hay cuatro esculturillas de Santos. La estructura arquitectónica, de composición circular, ostenta cuatro pares de pilastras con volutas inferiores. Se cubre con casquete esférico. Y en su interior aparece una Virgen Hodegetria (fig. 7), coronada. En su indumentaria carmelitana despunta el escapulario. En origen, como dispensadora de todas las gracias, María debió portar el cetro en su mano derecha. Y el pequeño Jesús, desnudo, con la bola del mundo en la mano izquierda, refuerza la idea de la verdadera carne de Cristo, nacida de María Virgen, que se hace presente en la eucaristía ${ }^{27}$. Simboliza la humillación del Hijo de Dios que oculta no solo su divinidad, sino hasta su humanidad. Sintetiza, por fin, una triple y simbólica desnudez: nuditas naturalis, temporalis et virtualis, es decir, representa el estado natural del hombre recién nacido, pureza, e inocencia de vida ${ }^{28}$.

Las figuras de los ángulos representan a San Juan de la Cruz, a Santa Catalina de Siena, a Santo Tomás de Aquino y a Santa Teresa de Jesús. Por tanto, son dos santos de la Orden dominica y otros dos de la Orden carmelitana, de probada vinculación a la Eucaristía ${ }^{29}$. Los cuatro santos han resultado ser declarados Doctores de la Iglesia, a lo largo de la historia: Santo Tomás de Aquino, por San Pio V, el 11 de abril de 1567; San Juan de la Cruz, por Pio XI, el 24 agosto de 1926; Santa Teresa de Jesús, por Pablo VI, el 27 de septiembre de 1970; y Santa Catalina de Siena, la última Doctora, por Paulo VI, el 4 de octubre de $1970 .{ }^{30}$

Todo el conjunto se corona con una cúpula, que se fija a las pilastras inferiores con pequeñas perinolas pareadas. El elemento cupuliforme se decora con cuatro gallones, y cartelas y cabujones de esmalte entre ellos. En el total resultante sobresale la escultura itinerante de San José con el Niño Jesús (fig. 8). La figura del Santo Patriarca aparece como protector y custodio de Jesús, aplicándosele la alabanza bíblica de aquel otro José, el de Egipto: «Te hizo Dios como Padre del Rey y Señor de toda su casa" ${ }^{31}$. Aparece, además, como devoción predilecta de la Orden carmelita reformada. Santa Teresa nunca separaba a Santa María de su esposo San José, y así lo encargó a sus hijas e hijos del Carmelo ${ }^{32}$.

27. GONZÁLEZ GÓMEZ, Juan Miguel, Manuel Jesús CARRASCO TERRIZA, Escultura Mariana Onubense, $2^{\mathrm{a}}$ ed., Huelva, 1992, págs. 331-332.

28. GONZÁLEZ GÓMEZ, Juan Miguel, La escultura de Juan Abascal Fuentes en Huelva e Hispanoamérica, en Actas de las VI Jornadas de Andalucía y América. Sevilla, 1984. Tomo I, pág. 296.

29. FERRANDO ROIG, Juan, Iconografía de los Santos, Barcelona, 1950, págs. 71, 159-160, $254-255$ y 260.

30. TURRADO TURRADO, A., Doctor de la Iglesia, en GER, 8, 38-39

31. Responsorio del Oficio de Lecturas de la Solemnidad de San José. Cfr. Gen. 45, 8.

32. Cfr., Vida, cap. VI, 6-8. Relaciones espirituales, XXX, XXXVIII. Avisos, 65. 


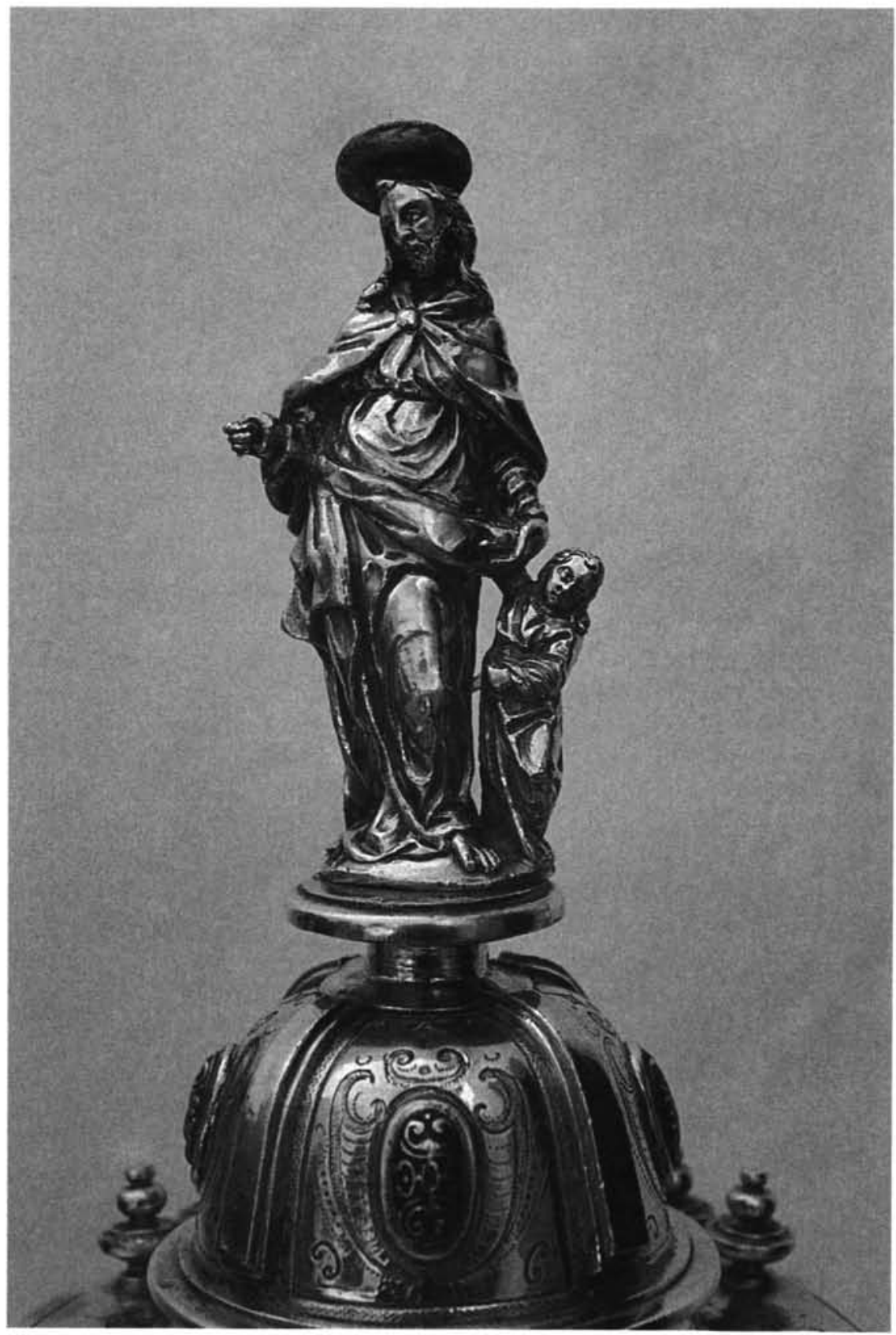

Fig. 8. Escultura josefina que remata el Templete-Ostensorio. 
Desde el punto de vista estilístico todos los elementos estructurales y decorativos nos remiten al estilo purista. La ordenación racional y simétrica, de ritmo cuaternario, subraya la armoniosa belleza del conjunto. Las cartelas, botones de esmalte nielado, gallones, asas, paños colgados, etc., abundan sobre el particular. $\mathrm{Y}$ las esculturas que constituyen el programa iconográfico del templete obedecen a los criterios compositivos del Bajo Renacimiento. Así lo acreditan el marcado contrapposto, el movimiento espiral de las efigies, el carácter heroico de las mismas, el plegado de las telas, etc.

La procedencia de la pieza queda perfectamente documentada como obra de platería mejicana, gracias al punzón de la ciudad de México (fig. 9) que se repite por tres veces. Dicha marca se compone de una $M$ con una pequeña $O$ superpuesta, sobre la que aparece una cabeza humana de perfil. Todo ello queda flanqueado por dos columnas, y rematado por una corona de tres puntas. Los punzones se hallan en la plataforma del cuerpo inferior del templete, tras la figura de San Agustín; en la base circular del segundo cuerpo, tras la Virgen Hodegetria; y, por último, en el plinto del remate cupuliforme que corona todo el templete, a la espalda de San José. Se trata de una marca de contraste, que garantiza la ley del metal empleado. La pieza carece, en cambio, de marcas de artífice, que nos permitan establecer su autoría.

Contribuye a fijar la datación de este ejemplar de orfebrería mejicana, la morfología manierista, que en Hispanoamérica se prolonga a lo largo de todo el siglo XVII, y la beatificación de San Juan de la Cruz, que tuvo lugar el 25 de enero de $1675^{33}$.

Una pieza, con la que la de Villarrasa alcanza singular parangón, posiblemente de la misma mano o taller, es la custodia de la iglesia de Santa María de Busturia (Vizcaya), adquirida a la Catedral de San Luis de Potosí, y labrada en la capital de México hacia 1670, algo mayor que la de Villarrasa, pero ambas calificables como "de las creaciones más perfectas y originales salidas de los obradores mexicanos» ${ }^{34}$. Con Esteras Martín, concluimos que «el platero denota conocimientos muy notables de composición y dibujo, y una expresividad inigualable en el vocabulario manierista. El nombre de un artífice con estas condiciones creadoras bien valía la pena haberse conocido» ${ }^{35}$.

33. Cfr. CRISÓGONO DE JESÚS, Vida y Obras de San Juan de la Cruz BAC. Madrid, 1964, pág. 10.

34. ESTERAS MARTÍN, Cristina, Orfebrería hispanoamericana. Siglos XVI-XIX, Católogo de la Exposición. Museo de América. Instituto de Cooperación Iberoamericana. Madrid, diciembre 1986, págs. 35-37. Mide $93 \mathrm{cms}$. de altura; $35 \mathrm{cms}$. de base.

35. Ibídem, pág. 37. 


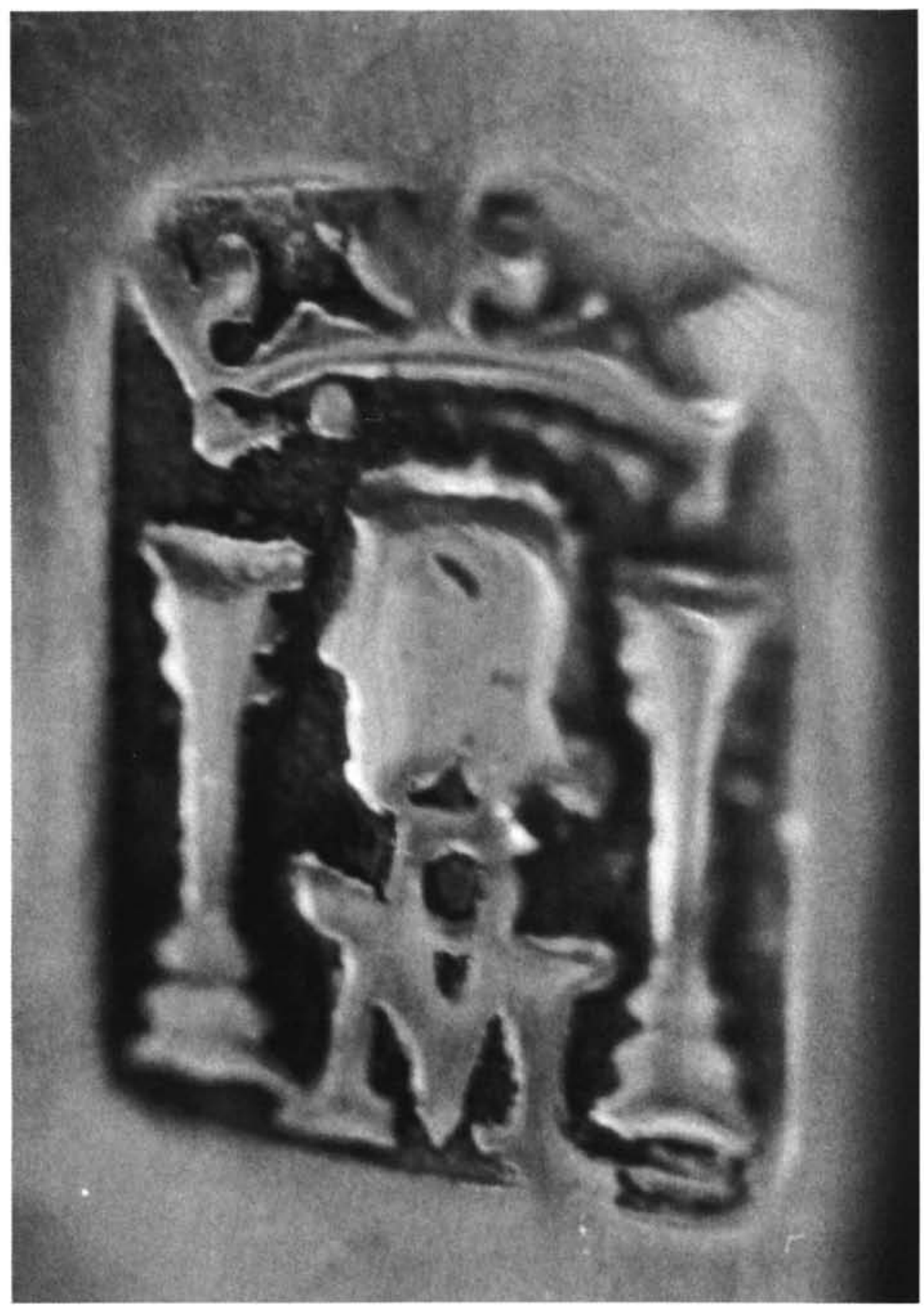

Fig. 9. Punzón de la ciudad de México del Templete-Ostensorio. 
Al no haber sido catalogada hasta ahora este conjunto de platería mexicana, explica que no figurara en su integridad en la exposición de Plata Labrada de Indias. Los legados americanos en las iglesias de Huelva. Ahora, afortunadamente, podemos hacer justicia y reparar la omisión, dando a conocer el legado de Pedro Ximénez Delgado a la Virgen de los Remedios de Villarrasa — frontal, cáliz, salvilla, par de blandones, etc.- - y el templete-ostensorio de la parroquial de San Vicente Mártir de Villarrasa, como piezas anónimas de los talleres que florecieron en Méjico a lo largo del Seiscientos. 